ORNL/TM-2019/1117

CRADA/NFE-18-07361

\title{
Additive Manufacturing Using Epoxy and Anhydride Curatives
}

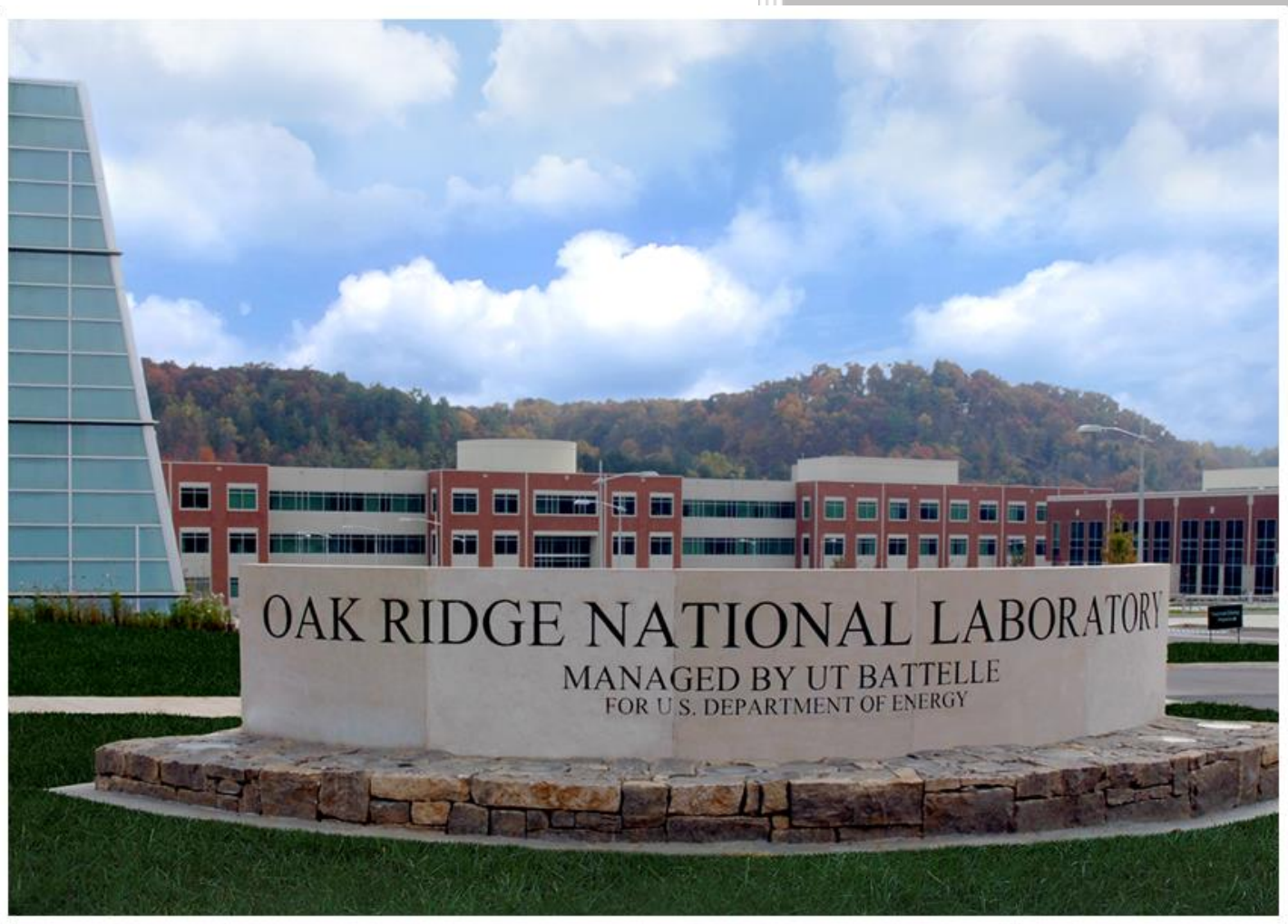

John Lindahl

February $4^{\text {th }}, 2019$

Approved for Public Release. Distribution is Unlimited. 


\section{DOCUMENT AVAILABILITY}

Reports produced after January 1, 1996, are generally available free via US Department of Energy (DOE) SciTech Connect.

Website http://www.osti.gov/scitech/

Reports produced before January 1, 1996, may be purchased by members of the public from the following source:

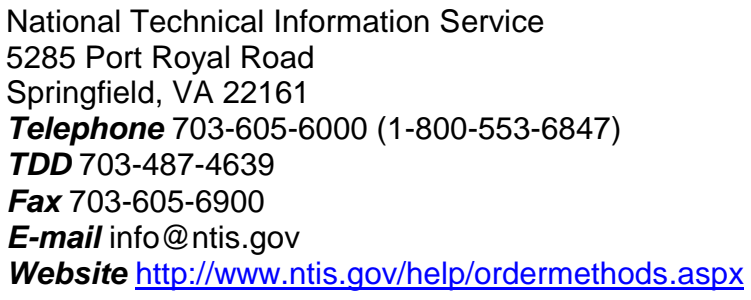

Reports are available to DOE employees, DOE contractors, Energy Technology Data Exchange representatives, and International Nuclear Information System representatives from the following source:

Office of Scientific and Technical Information

PO Box 62

Oak Ridge, TN 37831

Telephone 865-576-8401

Fax 865-576-5728

E-mail reports@osti.gov

Website http://www.osti.gov/contact.html

This report was prepared as an account of work sponsored by an agency of the United States Government. Neither the United States Government nor any agency thereof, nor any of their employees, makes any warranty, express or implied, or assumes any legal liability or responsibility for the accuracy, completeness, or usefulness of any information, apparatus, product, or process disclosed, or represents that its use would not infringe privately owned rights. Reference herein to any specific commercial product, process, or service by trade name, trademark, manufacturer, or otherwise, does not necessarily constitute or imply its endorsement, recommendation, or favoring by the United States Government or any agency thereof. The views and opinions of authors expressed herein do not necessarily state or reflect those of the United States Government or any agency thereof. 
ORNL/TM-2019/1117

CRADA/NFE-18-07361

Materials Science and Technology Division Advanced Manufacturing Office

\title{
Additive Manufacturing Using Epoxy and Anhydride Curatives
}

\author{
Authors \\ John Lindahl \\ Christopher Hershey \\ Vlastimil Kunc \\ Gary Gladysz \\ Vinay Mishra \\ Karana Shah
}

Date Published:

February $4^{\text {th }}, 2019$

\author{
Prepared by \\ OAK RIDGE NATIONAL LABORATORY \\ Oak Ridge, Tennessee 37831-6283 \\ managed by \\ UT-BATTELLE, LLC \\ for the \\ US DEPARTMENT OF ENERGY \\ under contract DE-AC05-00OR22725
}

Approved For Public Release 



\section{CONTENTS}

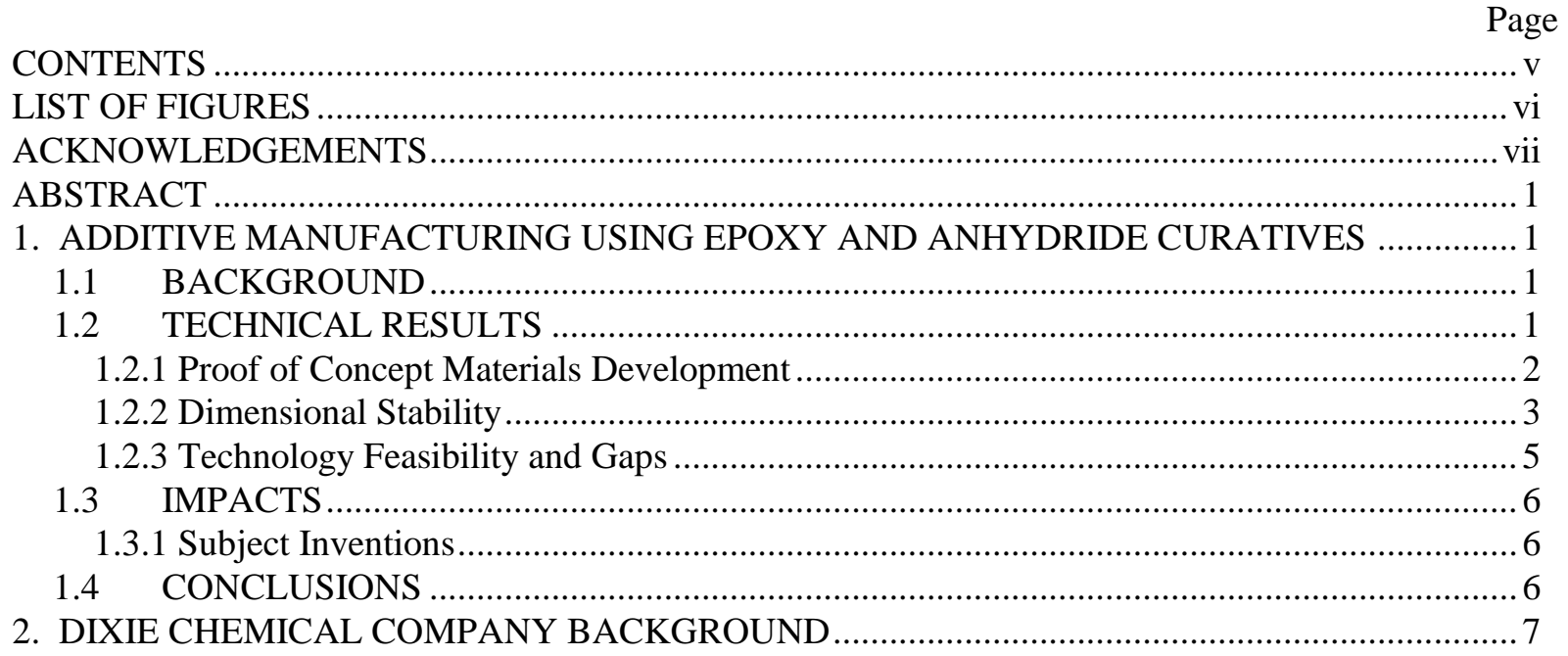




\section{LIST OF FIGURES}

Fig 1. Strain sweep test of epoxy (Epon 828) with anyhdride (ANH1) with varying weight ratios of clay showing effect on (left) storage and loss moduli and (right) complex viscosity. 2 Fig 2. Frequency sweep test of epoxy (Epon 828) with anyhdride (ANH1) with varying weight ratios of clay showing effect on (left) storage and loss moduli and (right) complex viscosity

Fig 3. Determination of yield stress, indicated by dashed line, from steady shear stress sweep for Epon 828 with ANH1 and $15 \mathrm{wt} \%$ clay. Yield stress is measured at $5700 \mathrm{~Pa}$.

Fig 4. Squeeze flow tests at discrete stress loads to determine change in gap height below and above the material yield stress. The material tested was Epon 828 with ANH1 and $15 \mathrm{wt} \%$ clay

Fig 5. Dynamic mechanical analysis by torsion of Diacel Celloxide with ANH3 and 15 wt\%

clay.

Fig 6. DMA sample during deposition. Material is Diacel Celloxide with ANH1 and 15wt\% clay. 


\section{ACKNOWLEDGEMENTS}

This CRADA NFE-18-07361 was conducted as a technical collaboration project within the Oak Ridge National Laboratory (ORNL) Manufacturing Demonstration Facility (MDF) sponsored by the US Department of Energy Advanced Manufacturing Office (CPS Agreement Number 24761).

Opportunities for MDF technical collaborations are listed in the announcement "Manufacturing Demonstration Facility Technology Collaborations for US Manufacturers in Advanced Manufacturing and Materials Technologies" posted at http://web.ornl.gov/sci/manufacturing/docs/FBO-ORNL-MDF2013-2.pdf. The goal of technical collaborations is to engage industry partners to participate in shortterm, collaborative projects within the Manufacturing Demonstration Facility (MDF) to assess applicability and of new energy efficient manufacturing technologies. Research sponsored by the U.S. Department of Energy, Office of Energy Efficiency and Renewable Energy, Advanced Manufacturing Office, under contract DE-AC05-00OR22725 with UT-Battelle, LLC. 


\begin{abstract}
ORNL worked with Dixie Chemical Company to develop epoxy material solutions with anhydride curatives printable on a large-scale printer. Rheological evaluation showed that the addition of high surface area fillers produced a stable yield-stress fluid that is capable of being used in extrusion deposition additive manufacturing. The resulting printed structures have the necessary mechanical and thermomechanical performance to be used in elevated temperature tooling for various composites processing, such as an autoclave.
\end{abstract}

\title{
1. ADDITIVE MANUFACTURING USING EPOXY AND ANHYDRIDE CURATIVES
}

This Phase 1 technical collaboration project (MDF-TC-2018-152) was begun on August 29 ${ }^{\text {th }}, 2018$ and completed on February $4^{\text {th }}, 2019$. The collaboration partner, Dixie Chemical Company, is a small business. Epoxy and anhydride compositions were successfully turned into 3D printable formulations through rheology modification using high surface area fillers.

\subsection{BACKGROUND}

Dixie Chemical has been in the chemical manufacturing business and global chemicals industry for over 70 years. It was founded in 1946 and has been part of Pasadena, Texas' Bayport Industrial District for about 50 years. From this 50-acre facility, Dixie Chemical supplies over 300 customers in more than 25 countries.

Most relevant to this CRADA, Dixie Chemical is a global supplier of a wide range of anhydride curatives and specialty chemicals for the composites industry. Anhydride-cured epoxies are high performance materials finding applications that require high temperature and chemical resistance. Dixie Chemical is uniquely positioned in the composites market; it routinely partners with resin, fiber, and/or particle manufacturers to develop customer-specific composite formulations. Phase 1 of this technical collaboration demonstrated that epoxies with anhydride curatives could be used as a matrix material for additive manufacturing. Through rheological evaluation and additive manufacturing of test specimens, it was shown that these materials are suitable for extrusion deposition additive manufacturing of thermoset materials.

\subsection{TECHNICAL RESULTS}

Phase 1 of this technical collaboration consisted of three main tasks. In Task 1.1, ORNL and Dixie Chemical Company worked together to develop proof of concept yield stress materials from standard epoxy and anhydride mixes. In Task 1.2, the dimensional stability of the compositions was evaluated both before and after curing through rheological testing and glass transition characterization, respectively. Task 1.3 explored the final composition performance with respect to the target goal of elevated temperature composite tooling. Mechanical and thermomechanical evaluation was utilized to confirm feasibility. Health and safety requirements for use of this material in additive manufacturing was also explored and documented. 


\subsubsection{Proof of Concept Materials Development}

Printability of reactive polymer systems has been successful when the feedstock material is shear thinning and has a yield stress i.e., Bingham plastics. The epoxy and anhydride material formulations investigated were shear thinning fluids consisting of a low viscosity ( $<5 \mathrm{~Pa} \cdot \mathrm{s})$ but exhibited no yield stress, thus requiring the addition of secondary phase reinforcements for printability. Structural reinforcement using large surface area montmorillonite clay led to the formation of a filler network resulting in a significant increase in the epoxy/anhydride moduli and viscosities. Modification of the rheology by the addition of various weight ratios of the clay filler were first assessed using strain sweep tests from $0.01-100 \%$ strain at $1 \mathrm{rad} / \mathrm{s}$ using a TA Instruments DHR-2 with parallel plate fixture; the results are shown in Fig. 1.
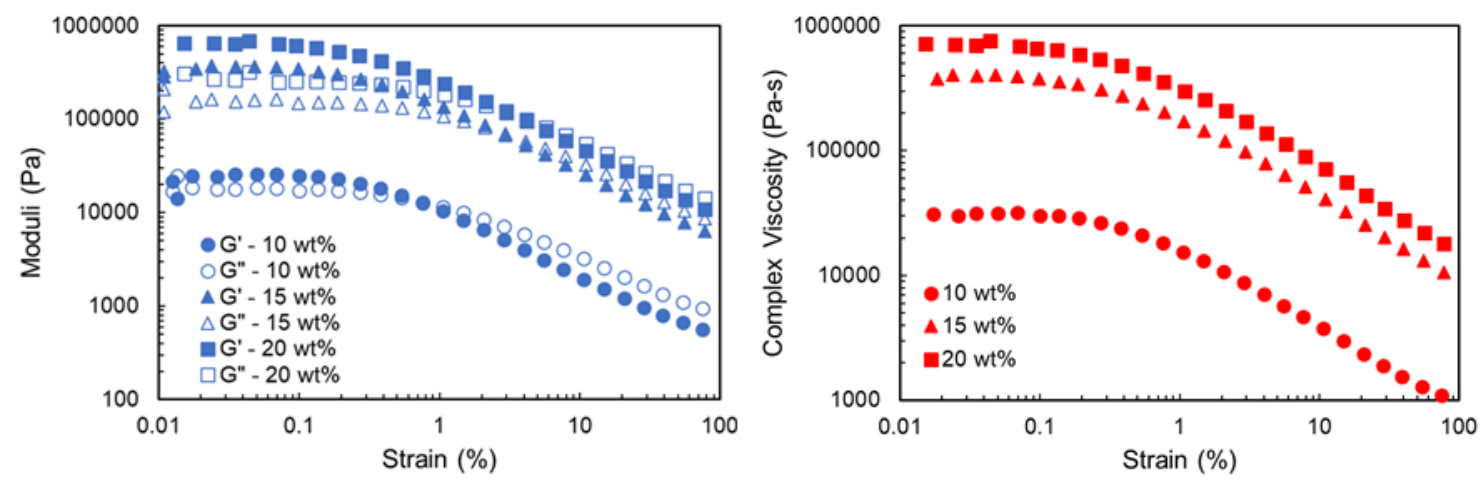

Fig. 1. Strain sweep test of epoxy (Epon 828) with anhydride (ANH1) with varying weight ratios of clay showing effect on (left) storage and loss moduli and (right) complex viscosity.

The comparison of 10, 15, and $20 \mathrm{wt} \%$ clay in Fig. 1 shows little effect on the rheology above $15 \mathrm{wt} \%$ clay due to the jamming of adjacent filler particles. Additionally, the corresponding frequency dependence was investigated from $0.1-100 \mathrm{rad} / \mathrm{s}$ at $0.03 \%$ strain and shown in Fig. 2.
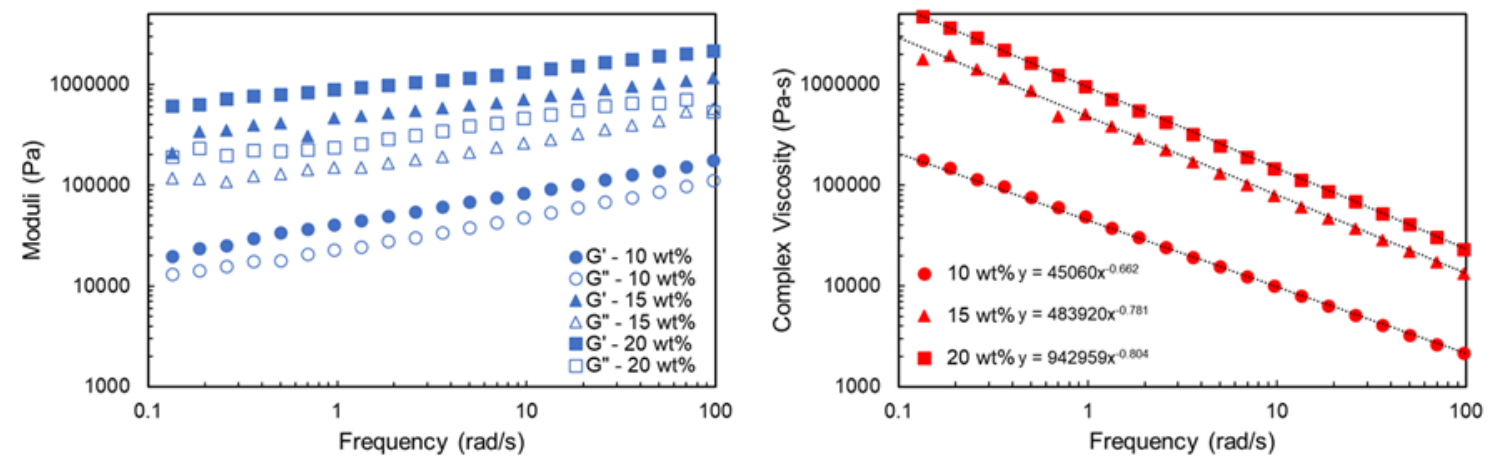

Fig. 2. Frequency sweep test of epoxy (Epon 828) with anyhdride (ANH1) with varying weight ratios of clay showing effect on (left) storage and loss moduli and (right) complex viscosity.

A power law model was used to fit the complex viscosity in Fig. 2 in order to quantify the effect of clay on the thinning behavior observed. As expected, there is an increase in the shear thinning effect with increasing weight fractions of clay, which is expected to improve printability by improving the pressure induced flow through the printer. Using the information from Figs. 1 and 2, 
the choice of $15 \mathrm{wt} \%$ was made for further material testing and dimensional stability.

\subsubsection{Dimensional Stability}

In Section 1.2.1 it was established that the addition of clay filler increased rheological properties and induced greater shear thinning behavior due to the breakup of filler network during flow. The formation of a filler network microstructure had the observable effect of imparting a yield stress during shear stress sweeps of the epoxy/anhydride formulations. Yield stress is the amount of stress required to force a material to flow, and it is required to maintain a printed bead cross section during deposition of successive layers. A steady shear stress sweep was performed to determine the yield stress of the epoxy anhydride composite formulations. The result for Epon 828/ANH1/15 wt\% clay is shown in Fig. 3; the vertical dashed line indicates the yield stress for that formulation.

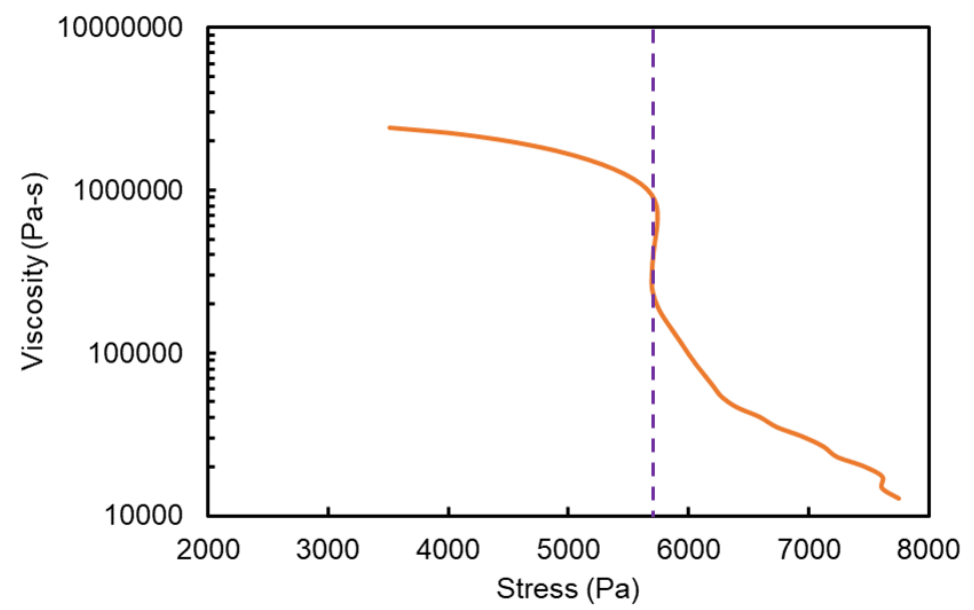

Fig. 3. Determination of yield stress, indicated by dashed line, from steady shear stress sweep for Epon 828 with ANH1 and 15wt\% clay. Yield stress is measured at $5700 \mathrm{~Pa}$.

Determination of the yield stress from Fig. 3 is marked as the stress at which the viscosity shows a substantial decrease (catastrophic yield). Additional "yielding" is observed at lower stresses due to restructuring and alignment of the filler particles.

To confirm the yield behavior as it applies to 3D printing, an axial compression test known as a squeeze flow test was performed to emulate the compressive load a bead will encounter during subsequent depositions. The corresponding squeeze flow test to Fig. 3 is shown in Fig 4. 


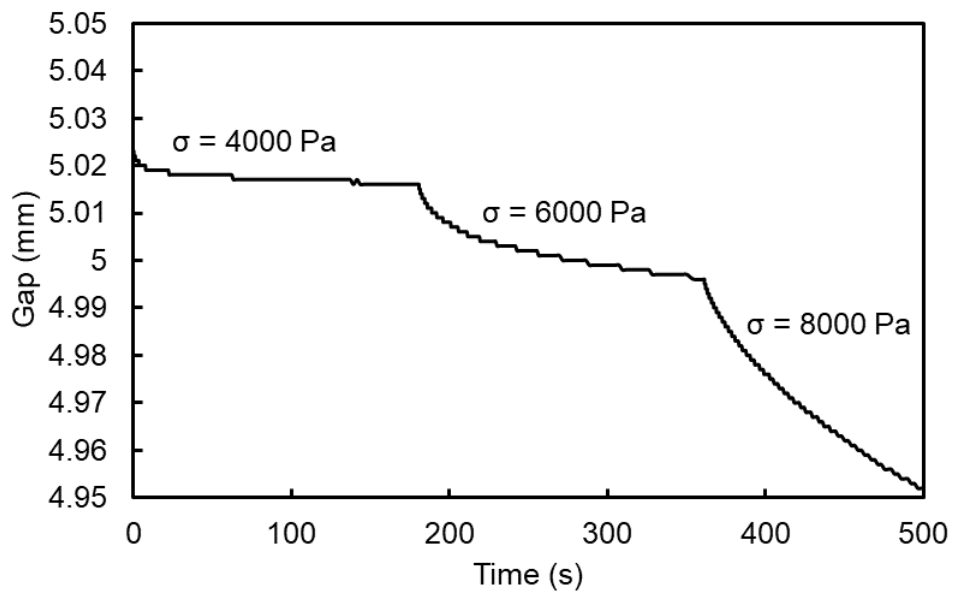

Fig. 4. Squeeze flow tests at discrete stress loads to determine change in gap height below and above the material yield stress. The material tested was Epon 828 with ANH1 and $15 \mathrm{wt} \%$ clay.

Squeeze flow tests, such as that presented in Fig. 4, help determine the stability of a printed part by providing information on the relative change in bead height as a function of time. The yield stress and change in bead height with time govern the maximum part size available for printing. For dimensional stability both in bead shape and final part, a large yield stress is desired with the gap change remaining nearly independent with time. These factors are also temperature and ageing dependent, which will be investigated in Phase 2.

Glass transition temperature is a major factor in determining the viability of a polymer to be used at elevated temperatures. The glass transition temperature of the printed materials was analyzed by dynamic mechanical analysis (DMA) using torsion bars with a $0.01 \%$ strain, an angular frequency of $10 \mathrm{rad} / \mathrm{s}$, and a temperature ramp of $2{ }^{\circ} \mathrm{C} / \mathrm{min}$. Fig. 5 shows a typical curve generated from a DMA analysis.

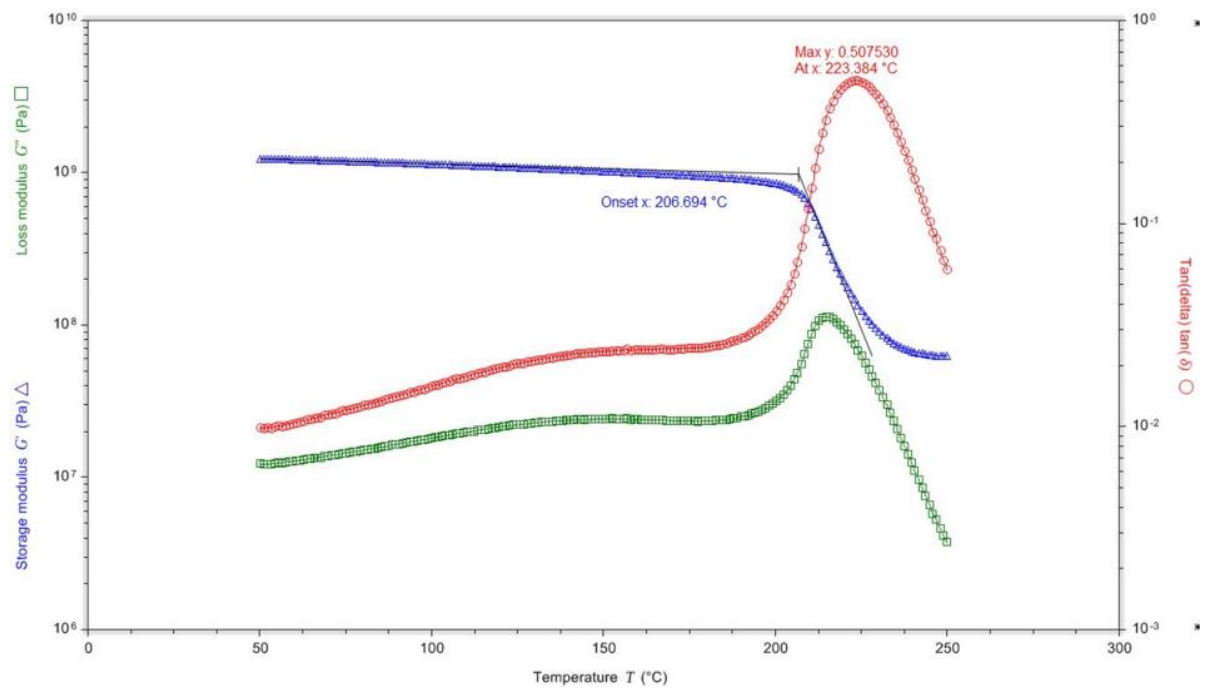

Fig. 5. Dynamic mechanical analysis by torsion of Diacel Celloxide with ANH3 and 15 wt $\%$ clay. 
From these tests, two glass transition temperatures are measured. The first glass transition is the onset of the storage modulus drop, and the second is the peak of the $\tan \delta$ curve. The material shown has onset glass transition at $206.7^{\circ} \mathrm{C}$ and a $\tan \delta$ peak at $223.4^{\circ} \mathrm{C}$, which would allow this material to be used in composite tooling applications.

In this task, secondary equipment was also evaluated. Bytac, a product of Saint Gobain, was used as the build substrate. This is a coated aluminum tape that can withstand the curing of the printed materials and allow for easy removal while being reusable. Acetone was used as a solvent to clean any uncured material. A Nordson EFD HPx mounted on a Shopbot D2418 motion platform was used to dispense the mixed material. Fig. 6 below shows printed material from this platform.

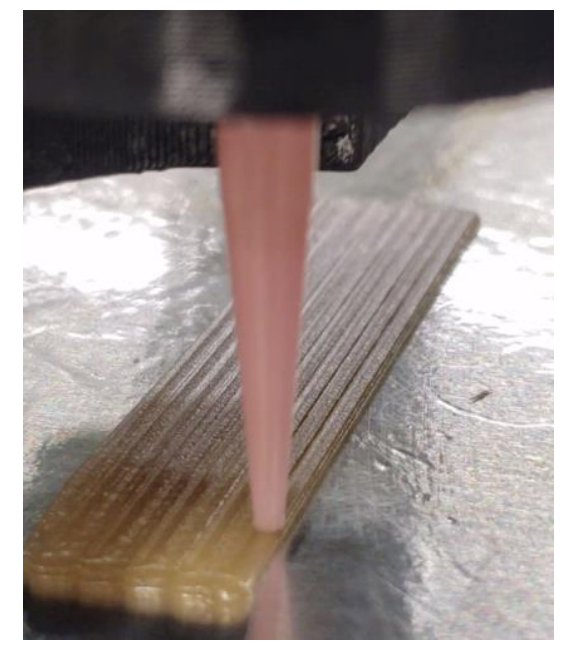

Fig. 6. DMA sample during deposition. Material is Diacel Celloxide with ANH1 and 15 wt $\%$ clay.

\subsubsection{Technology Feasibility and Gaps}

Mechanical and thermomechanical performance are key to using a polymer system for elevated temperature composite tooling. From Tasks 1.2.1 and 1.2.2 Diacel Celloxide was chosen as the base epoxy system to be further investigated with the four anhydride curatives. Three-point bend flexural test samples were printed utilizing Diacel Celloxide and the four different anhydrides with $15 \mathrm{wt} \%$ clay in all samples. The samples all had deposition oriented along their length. Table 1 below shows the average flexural strength and modulus for the four different sample sets. Standard autoclave operating pressure ranges from 30 to $100 \mathrm{psi}$. The flexural strength and stiffness of these printed materials would be sufficient to withstand these pressures when in use. Linear coefficient of thermal expansion was also measured for the best thermal performing combination, Diacel Celloxide and ANH3. In plane along the deposition direction $\alpha=51.17 \mu \mathrm{m} / \mathrm{m}-{ }^{\circ} \mathrm{C}$, in plane perpendicular to the deposition direction $\alpha=70.03 \mu \mathrm{m} / \mathrm{m}-{ }^{\circ} \mathrm{C}$, and normal to the build plane $\alpha=54.90 \mu \mathrm{m} / \mathrm{m}-{ }^{\circ} \mathrm{C}$.

Table 1. Three-point bend flexural data

\begin{tabular}{|c|c|c|c|c|}
\hline Curative & Strength $(\mathrm{MPa})$ & $\begin{array}{c}\text { Standard } \\
\text { Deviation }\end{array}$ & Modulus (GPa) & $\begin{array}{c}\text { Standard } \\
\text { Deviation }\end{array}$ \\
\hline ANH1 & 96.23 & 5.05 & 4.27 & 0.11 \\
\hline ANH2 & 95.84 & 7.48 & 3.42 & 0.51 \\
\hline ANH3 & 99.16 & 6.90 & 3.69 & 0.29 \\
\hline ANH4 & 90.45 & 10.13 & 4.13 & 0.17 \\
\hline
\end{tabular}


In order to print these materials, the Shopbot deposition platform was moved to the ventilation booth to have proper ventilation for deposited materials. When this technology is transferred to the large-scale thermoset printer, it is believed that no additional modifications will be needed to the current air ventilation system to satisfy any health and safety concerns.

\subsection{IMPACTS}

This project contributed significantly to the understanding of additive manufacturing with latent cure reactive polymer systems. Characterization methods were developed to qualify materials in their uncured state for additive manufacturing without the need for trial and error approaches. It also proved that standard off the shelf systems could be modified to produce a printable material that opens new areas of use. This will also allow the direct digital manufacturing of thermoset composite tooling for elevated temperatures well above the current thermoset materials that can be printed. Based on the results from Phase 1, Dixie Chemical Company would like to move forward with Phase 2 of this technical collaboration. Follow on efforts will include the formulation of commercial-ready printable material using additional solids, modifying deposition equipment, and working toward an industrial application.

\subsubsection{Subject Inventions}

There are no subject inventions as a result of this project.

\subsection{CONCLUSIONS}

ORNL and Dixie Chemical Company successfully turned a latent cured anhydride epoxy system into a viable additive manufacturing material. The low viscosity systems were turned into yield stress fluids by the addition of clay allowing for sequential deposition. This proved the feasibility of using these material systems on a larger scale.

In Phase 2 the scale-up of the technology for use on the MVP Thermobot will be evaluated. More rigorous analysis of printed materials will be performed. Other additives, such as hollow glass spheres will be investigated for light-weighting. Additively manufactured autoclave tooling from the developed material systems will also be tested to prove the real-world use of these material systems, thus opening a new market for Dixie Chemical Company to enter. 


\section{DIXIE CHEMICAL COMPANY BACKGROUND}

Dixie Chemical Company, Inc. (Dixie) has been in the chemical manufacturing business and global chemicals industry for over 70 years. It was founded in 1946 and has been part of Pasadena, Texas' Bayport Industrial District for about 50 years. From this 50-acre facility, Dixie Chemical supplies over 300 customers in more than 25 countries.

Dixie is a leading producer of epoxy curing agents and specialty chemicals for the thermoset and composite markets. Dixie offers a broad range of anhydride curing agents, reactive diluents, tougheners, resins, and bio-based raw materials. This Thermoset Materials line of products includes modified anhydrides, which combine the performance benefits of specialty additives such as accelerators and mold release agents.

Dixie has recently developed and commercialized a proprietary pre-catalyzed anhydride technology, leading to novel anhydride curing agents for epoxy composites. These products allow for epoxy formulations with low viscosities, long pot lives, fast cures, and high glass transition temperatures making them ideally suited for high-speed pultrusion processes to produce cost-efficient advanced composite components.

Through an Open Innovation platform, Dixie Chemical partners with other industry leading companies, universities, and government laboratories to jointly advance new chemistries, processing technologies, and markets for thermoset composites. 